\title{
Tetrahydrobiopterin Is Present in High Quantity in Human Milk and Has a Vasorelaxing Effect on Newborn Rat Mesenteric Arteries
}

\author{
ANGELA WEINMANN, MARTIN POST, JINGYI PAN, MAHROUKH RAFII, DEBORAH L. O'CONNOR, SHARON UNGER, \\ PAUL PENCHARZ, AND JAQUES BELIK
}

Department of Pediatrics [A.W.], Santa Maria Federal University, Santa Maria, Rio Grande do Sul, 97.105-900, Brazil; Physiology and Experimental Medicine Program [M.P., J.P., M.R., D.O., P.P., J.B.], Department of Pediatrics [S.U., P.P., J.B.], The Hospital for Sick

Children, Toronto, Ontario, M5G 1 X8 Canada

\begin{abstract}
Breast milk reduces the incidence of necrotizing enterocolitis (NEC). BH4 is a cofactor for endothelial NOS (eNOS). Reduced BH4 levels, or its oxidation to dihydrobiopterin (BH2), uncouple eNOS resulting in formation of reactive oxygen species (ROS) that have been implicated in the pathogenesis of NEC. We evaluated colostrum and mature breast milk, as well as infant formula, $\mathrm{BH} 4$ and $\mathrm{BH} 2$ content. In addition, we tested the $\mathrm{BH} 4$ effect on the newborn rat mesenteric arterial vascular tone. $\mathrm{BH} 4$ and $\mathrm{BH} 2$ content increased 3-fold in mature breast milk, when compared with colostrum $(p<0.01)$, without a change in their ratio. Infant formula had a negligible BH4 content and lower biopterins ratio, when compared with breast milk. eNOS is the predominant synthase isoform in newborn rat mesenteric arteries. In the presence of $\mathrm{BH} 4$, mesenteric arteries contracted less to thromboxane $A_{2}$ analog U46619 ( $p<0.01)$ and this effect was abolished following eNOS inhibition. BH4 $\left(10^{-6} \mathrm{M}\right)$ vasorelaxed the newborn rat mesenteric arteries. We conclude that when compared with infant formula, breast milk has a high BH4 content that increases as breastfeeding continues. Given its mesenteric arterial vasorelaxing effect, BH4 may play an important role in the reduced NEC incidence among breastfed infants. (Pediatr Res 69: 325-329, 2011)
\end{abstract}

$\mathrm{N}$ ecrotizing enterocolitis (NEC) is a serious clinical condition involving a significant number of preterm and term neonates (1). The disease is associated with high morbidity and mortality rates. Its etiology and pathogenesis remain elusive, precluding adequate prevention of this condition. Bowel mucosa ischemia with subsequent invasion of bacteria present in the intestinal flora, likely account for the clinical manifestations of the disease (2-4).

Breast milk feeding, when compared with the use of infant formula, seems to reduce the likelihood of NEC (1). However, the mechanism by which human milk prevents the disease is poorly understood. Although its immunological properties are often cited as the main reason for its beneficial effects against NEC, the composition of breast milk is quite distinct from infant formulas and these differences may also contribute to its disease protective effect. Identification of the factors in breast

Received July 29, 2010; accepted November 1, 2010.

Correspondence: Jaques Belik, M.D., Professor of Pediatrics and Physiology, University of Toronto, Division of Neonatology, The Hospital for Sick Children, 555 University Avenue, Toronto, Ontario, M5G 1X8 Canada; e-mail: jaques.belik@sickkids.ca

Supported by an operational grant from the Canadian Institutes of Health and Research, no. MOP 93710 [J.B.]. milk that contribute to its NEC preventive properties may allow for the further refinement of infant formulas to attain similar beneficial effects as human milk.

Biopterins are present in breast milk and are previously shown to enhance the mesenteric blood flow (5). Previous reports suggest that when compared with bovine-derived formulas, breast milk has a higher content of total biopterins (6). Biopterins encompass tetrahydropterin (BH4) and its oxidized 7,8 dihydrobiopterin form (BH2). $\mathrm{BH} 4$ is a required cofactor for endothelial NOS (eNOS) coupling and vascular generation of NO. In its absence, eNOS is said to be uncoupled generating mostly the reactive oxygen species (ROS) superoxide, instead of NO. Superoxide induces vasoconstriction and has been shown to play a role in animal models of $\operatorname{NEC}(7,8)$.

The main goal of this study was to evaluate the $\mathrm{BH} 4$ and BH2 concentrations in breast milk (colostrum and mature) from women in the immediate postpartum period, as well as commercial infant formulas. In addition, we sought to evaluate the $\mathrm{BH} 4$ effect on the newborn rat mesenteric arteries. We hypothesize that $\mathrm{BH} 4$ is present in human breast milk at a concentration higher than present in commercial infant formula and has a mesenteric arterial vasorelaxant effect in newborn rats.

\section{METHODOLOGY}

Human studies. Postpartum women with term or preterm gestation were enrolled in this study. Breast milk $(n=10)$ was obtained within the first $48 \mathrm{~h}$ of the postpartum period (colostrum) and during their first newborn follow-up outpatient clinic visit (1-2 wk of age-mature milk). In addition, three samples of mature (1-2 wk postpartum) breast milk was obtained from women delivering at 28-32 wk gestation. This study was approved by the Institutional Review Board of the Santa Maria Federal University, Santa Maria, Rio Grande do Sul, Brazil.

Breast milk. Breast milk was manually expressed in sterile containers wrapped with foil. Immediately after milking, $0.3 \mathrm{~mL} \mathrm{4 \%} \mathrm{(wt/vol)} \mathrm{DTT} \mathrm{was}$ added to $10 \mathrm{~mL}$ of human milk and centrifuged at $10,000 \times \mathrm{g}$ at $4^{\circ} \mathrm{C}$ for $1.5 \mathrm{~h}$. The upper fat layer was removed and the milk was centrifuged again for another $30 \mathrm{~min}$. The supernatant was collected and stored in dark vials at $-80^{\circ} \mathrm{C}$, until analysis.

Biopterin measurements. Biopterin concentrations were determined by liquid chromatography electrospray tandem mass spectrometry (LC-MS/MS). A triple quadrupole mass spectrometer API 4000 (Applied Biosystems/MDS

Abbreviations: BH2, 7,8 dihydrobiopterin; BH4, tetrahydropterin; eNOS, endothelial NOS; nNOS, neuronal NOS; NEC, necrotizing enterocolitis 
Sciex, Foster City, CA), operated in negative ionization mode with the TurboIonSpray ionization probe source and coupled to an Agilent 1100 HPLC system, (Agilent Technologies, Palo Alto, CA) was used. The method used a $\mathrm{C}_{18}$ column $(150 \times 2 \mathrm{~mm}$ i.d., $5 \mu \mathrm{m}$ particle size, and 110 $\AA$ pore size) with isocratic solvent system of water with $0.002 \%$ formic acid at $0.3 \mathrm{~mL} / \mathrm{min}$ and a runtime of $13 \mathrm{~min}$. All aspects of the system operation and data acquisition were controlled using Analyst NT Software (version 1.4.1; Applied Biosystems/MDS Sciex).

Calibrators were prepared by spiking pooled milk samples with 9 different concentrations: $0,0.5,1,5,10,20,50,70,140$, and $200 \mathrm{ng} / \mathrm{mL}$ of biopterin (Schirck Laboratories, Jona, Switzerland). The calibrators were treated the same as the unknown milk samples. Milk BH4 and $\mathrm{BH} 2$ concentration were measured after differential iodine oxidation as previously described (9). Under acidic conditions, $\mathrm{BH} 4$ and $\mathrm{BH} 2$ are oxidized to biopterin; on the other hand, $\mathrm{BH} 2$ is oxidized to biopterin under basic conditions. Hence, the difference in biopterin amounts between the two oxidations account for the BH4 amount. Briefly, for the acidic oxidation, $50 \mu \mathrm{L}$ of milk with corresponding calibrators, in $200 \mu \mathrm{L} 0.1 \mathrm{M} \mathrm{HCl}$ containing $0.02 \mu \mathrm{g} / \mathrm{mL}$ Rhamnopterin (internal standard; Chemos, $\mathrm{GmbH}$, Germany) were added to $100 \mu \mathrm{L}$ of iodine solution [2\% (wt/vol) K-Iodine and 1\% (wt/vol) iodine in $1 \mathrm{M} \mathrm{HCl}$. After $60 \mathrm{~min}$ in the dark and at room temperature, excess $\mathrm{I}_{2}$ was reduced by addition of 200 $\mu \mathrm{L}$ of $5 \%(\mathrm{wt} / \mathrm{vol}$ ) ascorbic acid in water. For the alkaline oxidation, $50 \mu \mathrm{L}$ of milk in $200 \mu \mathrm{L} 0.1 \mathrm{M} \mathrm{HCl}$ containing $0.02 \mu \mathrm{g} / \mathrm{mL}$ Rhamnopterin were added to $100 \mu \mathrm{L}$ of iodine solution [2\% (wt/vol) K-iodine and $1 \%(\mathrm{wt} / \mathrm{vol}$ ) iodine in $1 \mathrm{M} \mathrm{NaOH}$ ]. After $60 \mathrm{~min}$ in the dark at room temperature, the reaction was stopped adding $200 \mu \mathrm{L}$ of $5 \%$ (wt/vol) ascorbic acid in water and $100 \mu \mathrm{L} 2 \mathrm{M} \mathrm{HCl}$. All samples were centrifuged at $12,000 \mathrm{rpm}$ for $20 \mathrm{~min}$ at $4^{\circ} \mathrm{C}$. The decolourized supernatant was loaded onto a cation-exchange cartridge (Oasis MCX extraction cartridge; Waters, Mississauga, ON) and the bound substances eluded with $1 \mathrm{~mL}$ of $8 \%$ (vol/vol) ammonia solution in $25 \%$ methanol. After drying under nitrogen, the residue was reconstituted with 200 $\mu \mathrm{L}$ of $0.002 \%$ formic acid, and $20 \mu \mathrm{L}$ of each sample was used for LC-MS/MS analysis. BH4 level was calculated by subtracting the amount of oxidized form of biopterin following basic oxidation (BH2) by the amount of total biopterin following acidic oxidation.

Animal studies. Newborn (5-7 d old) Sprague Dawley rats (Charles River, ON, Canada) were studied. All procedures were conducted according to criteria established by the Canadian Council on Animal Care and were approved by The Hospital for Sick Children Research Institute Animal Care Committees.

Organ bath studies. Mesenteric artery ring segments (average diameter $80-100 \mathrm{~mm}$ and length $=2 \mathrm{~mm}$ ) were dissected free and mounted in a wire myograph (Danish Myo Technology A/S, Aarhus, Denmark). Isometric changes were digitized and recorded online (Myodaq, Danish Myo Technology A/S, and Aarhus, Denmark). Tissues were bathed in Krebs-Henseleit buffer ( $\mathrm{NaCl}, 115 \mathrm{mM} ; \mathrm{NaHCO}_{3}, 25 \mathrm{mM}$; $\mathrm{NaHPO}_{4}, 1.38 \mathrm{mM} ; \mathrm{KCl}, 2.51 \mathrm{mM}$; $\mathrm{MgSO}_{4}-7 \mathrm{H}_{2} \mathrm{O}, 2.46 \mathrm{mM} ; \mathrm{CaCl}_{2}, 1.91 \mathrm{mM}$; and dextrose, $5.56 \mathrm{mM}$ ) bubbled with air $/ 6 \% \mathrm{CO}_{2}$ and maintained at $37^{\circ} \mathrm{C}$. After $1 \mathrm{~h}$ of equilibration, the optimal tissue resting tension was determined by repeated stimulation with $128 \mathrm{mM} \mathrm{KCl}$ until maximum active tension was reached. All subsequent force measurements were obtained at optimal resting tension.

Mesenteric arterial muscle force generation was evaluated by stimulating with the thromboxane $\mathrm{A}_{2}$-mimetic U46619. Contractile responses were normalized to the tissue cross-sectional area as follows: (width $\times$ diameter) $\times 2$ and expressed as millinewtons per square millimeter. The force changes induced by $\mathrm{BH} 4$, either following precontraction with U46619 at concentrations equivalent to the $75 \%$ of maximum contraction $\left(\mathrm{EC}_{75}\right)$ or without agonist stimulation were obtained. BH4 and BH2 (Schircks Laboratories, Jona, Switzerland) were prepared fresh immediately before the experiments. The former was dissolved in water and sodium ascorbate $(0.14 \mathrm{mg} / \mathrm{mL})$ to ensure its stability, whereas $\mathrm{BH} 2$ was dissolved only in water.

Preparation of tissue extracts. Newborn rat small bowel and mesenteric arterial tissue extracts were obtained by using a lysis buffer containing $50 \mathrm{mM}$ Tris- $\mathrm{HCl}$, pH 7.5, $0.5 \mathrm{mM}$ sodium chloride, $10 \mathrm{mM}$ magnesium chloride, 1 mM EDTA, 1 mM EGTA, and protease Inhibitor cocktail complete mini(Roche Applied Science, Mannheim, Germany). Tissues were frozen in liquid nitrogen then ground with mortar and pestle before ice-cold lysis buffer was added. After $1 \mathrm{~h}$ on ice, the homogenates were centrifuged at 14,000 rpm for $20 \mathrm{~min}$. The supernatants as extracts were transferred to fresh tubes. Total protein concentration was measured according to the Bradford method (10).

Immunoblotting for eNOS and neuronal NOS. The tissue extracts were digested with Laemmle's sample loading buffer at $95^{\circ} \mathrm{C}$ for 5 min and electrophoresed on 7.5\% PAGE/SDS (polyacrylamide/SDS) gel. Proteins separated on the gel were electrotransferred to nitrocellulose membrane (Amersham Biosciences, Mississauga, Canada) at room temperature for $1 \mathrm{~h}$ at a constant voltage of $100 \mathrm{~V}$. The membranes were blocked by rocking with $5 \%$ nonfat dry milk in tris-buffered saline and tween 20 (TBS-T) $(20 \mathrm{mM}$
Tris- $\mathrm{HCl}, \mathrm{pH} 7.6,137 \mathrm{mM} \mathrm{NaCl}$, and $0.1 \%$ Tween-20) for $1 \mathrm{~h}$ at room temperature. The trans-blots were then incubated at $4{ }^{\circ} \mathrm{C}$ on a rocking platform overnight with commercially available polyclonal antibodies raised against eNOS and neuronal NOS (nNOS; BD Transduction Laboratories; Mississauga, ON, Canada), both at a dilution of 1:1000. After washing with TBS-T for $30 \mathrm{~min}$, the trans-blots were incubated with $\mathrm{IgG}$ conjugated with horse radish peroxidase (Calbiochem; Gibbstown, NJ) dilution 1:10,000 in TBS-T containing 5\% milk at room temperature for $60 \mathrm{~min}$ and washed again with TBS-T for $40 \mathrm{~min}$ at room temperature. Subsequently, treatment of the membranes with enhanced chemiluminescent (ECL; Perkin Elmer, Shelton, $\mathrm{CT}$ ) reagent produced the signal that was transferred on to the Kodak scientific imaging film. The membrane blots were stripped then exposed to $\beta$-actin at a dilution of $1: 10,000$. The eNOS and nNOS bands on imaging film were quantitated by measuring their densities (ImageJ software, National Institutes of Health) and expressed as a ratio of the corresponding $\beta$-actin (dilution 1:40.000; Sigma Chemical Co. Aldridge, Oakville, ON, Canada) densities.

Drugs and infant formula. Unless otherwise indicated, all drugs were obtained from Sigma Chemical Co. Aldrich (Oakville, ON, Canada). The commercial ready-to-feed formulas for term and preterm infants used to measure biopterins content were, respectively, Enfamil A+ with Iron and Enfamil Preterm, both having $24 \mathrm{Kcal} / 30 \mathrm{~mL}$ (Mead Johnson Nutritional Company, Ottawa, ON, Canada).

Data analysis. Data were evaluated by one- or two-way ANOVA with multiple comparisons obtained by the Tukey-Kramer test or unpaired $t$ test when appropriate. Statistical significance was accepted at $p<0.05$. All statistical analyses were performed with the Number Cruncher Statistical System (NCSS, Kaysville, UT). Data are presented as means \pm SEM.

\section{RESULTS}

Human milk and biopterin content. Breast milk was obtained from 10 women with a GA of $38 \pm 1$ wk. Colostrum (postpartum day $2 \pm 0 ; n=9$ ) and mature milk (postpartum day $15 \pm 4 ; n=6$ ) were available for analysis. Mature breast milk BH4 content was significantly higher $(p<0.01)$ when compared with colostrum, whereas the $\mathrm{BH} 4 / \mathrm{BH} 2$ ratio of both milks were not statistically different (Fig. 1). We further evaluated the mature breast milk biopterin content of women delivering prematurely ( $28-32 \mathrm{wk} ; n=3)$. The BH4 content $(155 \pm 25 \mathrm{nmol} / \mathrm{L})$ was significantly lower $(p<0.01)$, whereas no difference in the $\mathrm{BH} 2(96 \pm 3 \mathrm{nmol} / \mathrm{L})$ and biopterins ratio $(1.6 \pm 0.3)$ were observed, when compared with milk from term gestation women.

When compared with colostrum or mature breast milk, the commercial formula showed very low $\mathrm{BH} 4$ content and most of the total biopterin was present as $\mathrm{BH} 2$, the oxidized biopterin form (Fig. $1, p<0.01$ ). There was not a statistically significant difference between the $\mathrm{BH} 4$ and $\mathrm{BH} 2$ content of

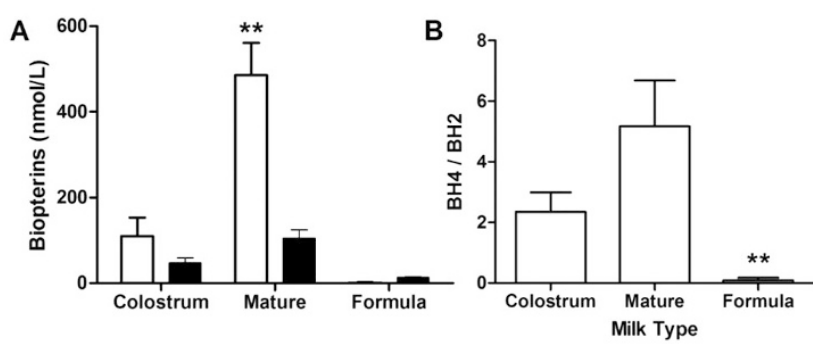

Figure 1. Breast milk and term infant formula $(A)$ tetrahydrobiopterin $(\mathrm{BH} 4 ; \square)$ and dihydrobiopterin $(\mathrm{BH} 2 ; \mathbf{\square}) * * p<0.01$ vs colostrum and infant formula, and $(B) \mathrm{BH} 4 / \mathrm{BH} 2$ ratio $* * p<0.01 v s$ infant formula by two-way and one-way, respectively, ANOVA and Tukey-Kramer multiple comparison testing. Colostrum, $n=9$; mature milk, $n=6$; and formula, $n=4$. 


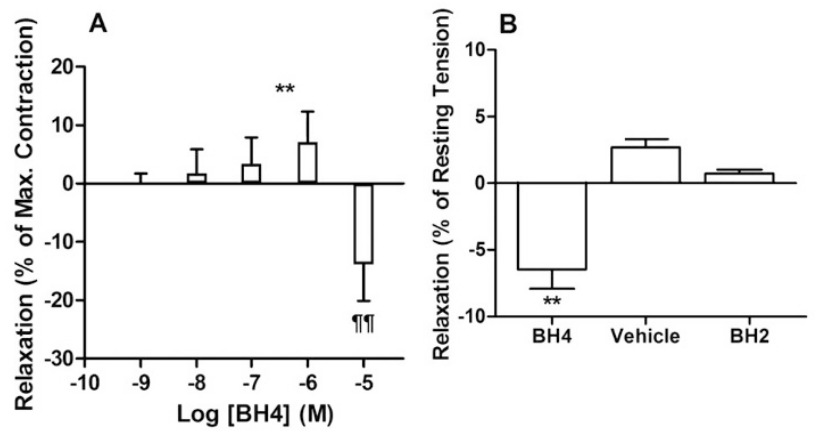

Figure 2. Tetrahydrobiopterin (BH4) effect on mesenteric arterial tone. (A) Newborn rat mesenteric arteries $(n=4)$ precontracted with the thromboxane $\mathrm{A}_{2}$ analog (U46619; $\mathrm{EC}_{75}=3-6 \times 10^{-8} \mathrm{M}$ ) and exposed to $\mathrm{BH} 4$ at increasing molar concentrations. ** $p<0.01 v s$ no BH4 and III $p<0.01 v s$ all other BH4 concentrations by one-way ANOVA and Tukey-Kramer multiple comparison testing. (B) Force changes induced by $\mathrm{BH} 4\left(10^{-4} \mathrm{M}\right)$, BH4-vehicle and BH2 $\left(10^{-4} \mathrm{M}\right)$ in newborn rat mesenteric arteries $(n=8)$ maintained at their resting tension. ${ }^{* *} p<0.01 v s$ no vehicle and $\mathrm{BH} 2$ by one-way ANOVA and Tukey-Kramer multiple comparison testing.

term $(0.6 \pm 1.4 \mathrm{nmol} / \mathrm{L}, 13 \pm 2 \mathrm{nmol} / \mathrm{L} ; n=4)$ and preterm $(0.4 \pm 1.7,13 \pm 1 ; n=3)$ formula samples.

Newborn rat mesenteric artery. $\mathrm{BH} 4$ induced a progressive and statistically significant relaxation of U46619 $\left(\mathrm{EC}_{75}=\right.$ 3-6 $\left.\times 10^{-8} \mathrm{M}\right)$ precontracted mesenteric arterial smooth muscle that was maximal at $10^{-6} \mathrm{M}$ concentration (Fig. 2, A). L-NAME $\left(10^{-4} \mathrm{M}\right)$ suppressed the BH4-induced mesenteric arterial vasorelaxation (data not shown).

Given that a significant contraction $(p<0.01)$ was noted at a higher $\mathrm{BH} 4$ concentration $\left(10^{-5} \mathrm{M}\right)$, (Fig. 2, A), we attempted to evaluate the mechanism responsible for this response. In not prestimulated mesenteric arteries (Fig. 2, B), whereas BH4induced contraction $\left(10^{-4} \mathrm{M}\right)$, neither the BH4-vehicle (ascorbic acid) nor $\mathrm{BH} 2\left(10^{-4} \mathrm{M}\right)$ induced any significant change in force. The BH4-induced mesenteric artery muscle contraction was not suppressed by L-NAME $\left(10^{-4} \mathrm{M}\right)$, indomethacin $\left(10^{-4} \mathrm{M}\right)$, or phentolamine $\left(10^{-5} \mathrm{M}\right)$, suggesting that it is unrelated to pathways involving NOS, prostaglandins, or adrenergic signaling respectively (data not shown).

In the presence of $\mathrm{BH} 4\left(10^{-6} \mathrm{M}\right)$, the thromboxane $\mathrm{A}_{2}$ analog (U46619)-induced force was significantly reduced in the newborn rat mesenteric arteries (Fig. 3). The BH4 effect on the U46619-induced force was abolished in the presence of L-NAME (data not shown).

To evaluate whether the $\mathrm{BH} 4$ effect on the mesenteric arteries was modulated via the eNOS or nNOS, we repeated the measurements in the presence of their respective inhibitors L-NIO $\left(10^{-4} \mathrm{M}\right)$ and 7-NINA $\left(10^{-5} \mathrm{M}\right)$. Although 7-NINAtreated vessels showed a similar force reduction pattern than untreated control arteries, this effect was abolished by the addition of $\mathrm{L}-\mathrm{NIO}\left(10^{-4} \mathrm{M}\right)$, suggesting that $\mathrm{BH} 4$ enhances the mesenteric vessel endothelial-derived NO generation via eNOS (Fig. 3).

Bowel and mesenteric arteries NOS isoform expression. The relative eNOS and nNOS protein expression was determined in newborn rat mesenteric arteries $(n=4)$ and small bowel $(n=3)$ tissue by Western blotting (Fig. 4$)$. Whereas no

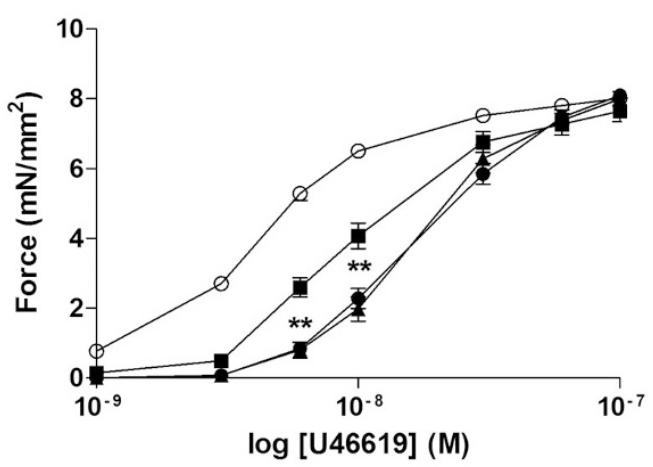

Figure 3. Tetrahydrobiopterin (BH4) effect on thromboxane $\mathrm{A}_{2}$-induced force. Newborn rat mesenteric arteries U46619 force development doseresponse in the absence (control; $n=12 ; \square)$, and presence of BH4 $\left(10^{-6} \mathrm{M}\right.$; $n=12 ; \boldsymbol{\Delta})$ alone and in combination with the nNOS (7-NINA $10^{-5} \mathrm{M} ; n=$ 8; ) and eNOS (L-NIO $10^{-4} \mathrm{M} ; n=4$; $\bigcirc$ ) inhibitors. ** $p<0.01$ vs control and all other groups by two-way ANOVA and Tukey-Kramer multiple comparison testing.

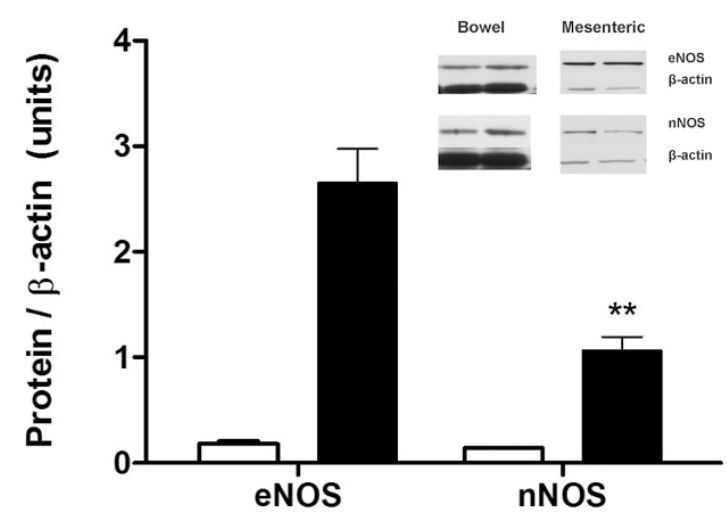

Figure 4. eNOS and nNOS western blotting. Newborn rat small bowel ( $\square$; $n=3)$ and mesenteric arterial $(\square ; n=4)$ tissue extract eNOS and nNOS protein content. Data expressed as a ratio of protein to $\beta$-actin densitometry reading in arbitrary units. Inset shows representative bands from each tissue. $* * p<0.01$ vs eNOS mesenteric arteries values.

significant difference in isoform expression was observed for the bowel, the eNOS protein content of the mesenteric arterial tissue was 2-fold greater than the nNOS densitometry values $(p<0.01)$. Together with the response to the specific NOS inhibitors, these data suggest that eNOS is the main isoform responsible for constitutive NO generation in the mesenteric vasculature.

\section{DISCUSSION}

The etiology of NEC is presently unknown, but its pathogenesis involves bowel ischemia leading to tissue necrosis in severe cases. Little is known about the factors accounting for the regulation of bowel blood flow in neonates. In piglets, NO is the main vasodilator of this vascular bed $(11,12)$. NOS isoforms are primarily responsible for vascular NO generation, and the activity of these enzymes depends on a number of associated molecules, among which $\mathrm{BH} 4$ is an important cofactor. 
Breast milk has been shown to reduce the incidence of NEC in neonates, when compared with infant formula feeding (1). The factors accounting for the beneficial effect of breast milk have not been fully identified. In newborn rats, breast milk has a protective effect against hypoxia- and cold-induced bowel ischemia (2). In this study, we documented that breast milk has a relatively high concentration of $\mathrm{BH} 4$ that increases during the transition from colostrum to mature milk. We further showed that exposure to $\mathrm{BH} 4$ reduces the newborn rat mesenteric arterial vascular tone, suggesting that it enhances NOS-mediated endogenous NO generation.

The NOS isoform responsible for the maintenance of a low mesenteric vascular tone under physiologic conditions is unknown. There is evidence that the nNOS isoform expression predominates in the adult rat small intestine (13), whereas others have implicated eNOS as responsible for the regulation of splanchnic blood flow in these animals (14) In this study, we documented that both NOS isoforms are present in the newborn rat's mesenteric arteries and bowel tissue, but eNOS predominates in the vascular tissue. Because the bowel tissue extract includes nonvascular cells, the NOS expression pattern of the mesenteric arteries is more representative of the bowel vasculature. In addition, we showed evidence in support of the BH4-induced mesenteric arterial vasorelaxation being mediated via eNOS activity. Such vasorelaxation was inhibitable, at concentrations previously shown to be effective (15), by a specific inhibitor of this isoform (L-NIO), but not by the nNOS blocker 7-NINA. Whether the NOS isoform expression and/or activity in the bowel vasculature are developmentally regulated in rats requires further investigation.

BH4 treatment has been shown to enhance intestinal perfusion in the adult rat experimental model of bowel ischemia and necrosis (16). In this study, we observed a similar effect in newborn rat mesenteric arteries, suggesting that this biopterin can increase splanchnic blood flow even under physiologic conditions. This effect, may in part account for the known breast milk protective effect against NEC in neonates. In fact, data obtained from piglets suggest that bowel mucosal blood flow is near maximal during milk feeding making this vascular bed very susceptible to ischemia (17).

The data from this study are in keeping with previous reports suggesting a higher biopterin concentration in human breast milk, when compared with animal-derived milk and commercial formula $(18,19)$. The total breast milk biopterins have been shown to increase in the immediate postpartum period and peak at $1 \mathrm{wk}$ (19). The biopterin content of breast milk obtained from women 1-11 mo postpartum was reported to be 10-fold higher than infant formula and some animals species (6). Matsubara et al., previously reported a total biopterin content of $50 \mathrm{nmol} / \mathrm{L}$ in commercial infant formula (6).

In these previous reports, however, the methodology used to evaluate the milk content allowed for reporting of only total biopterin concentrations. Breast milk $\mathrm{BH} 2$ content and the ratio of these two biopterins have not been previously reported. This is the first study to evaluate the breast milk and maternal content of both biopterins ( $\mathrm{BH} 4$ and $\mathrm{BH} 2)$, in addition to their ratio. We now show that not only the commercial infant formula total biopterins content is significantly lower than human breast milk, but also the BH4 content of infant formula is negligible likely due to this biopterin being oxidized to $\mathrm{BH} 2$ during the manufacturing process. This is of great functional relevance to the regulation of intestinal blood flow since $\mathrm{BH} 2$ has been shown to further uncouple NOS (20).

There is evidence that at least during adulthood in rodents, BH4 administered orally is taken up by absorption as efficiently as that injected intraperitoneally (21). A comparison of breast milk and formula on the human newborn mesenteric blood flow changes post feeding has been reported (22). The study showed no significant differences between these two types of milk; however, the Doppler methodology used by the investigators may not allow for proper assessment of the impact of milk containing biopterins on the splanchnic blood flow. The breast milk BH4 concentrations reported in this study ranged from 0.1 to $0.4 \mu \mathrm{M}$ and thus very close to the 1 $\mu \mathrm{M}\left(10^{-6} \mathrm{M}\right)$. BH4 concentration shown to induce mesenteric artery vasorelaxation in the newborn rat. Thus, the breast milk $\mathrm{BH} 4$ content is in the range where a vasodilatory effect on the bowel vasculature is possible.

Topical application of $\mathrm{BH} 4$ has been shown to induce cutaneous vasoconstriction in humans via adrenergic stimulation $(23,24)$. At a concentration greater than $10^{-5} \mathrm{M}$, we observed that $\mathrm{BH} 4$ can induce mesenteric arterial smooth muscle contraction in the newborn rat. The mechanism accounting for this $\mathrm{BH} 4$-induced vasocontraction is unclear, but unlikely related to NOS-derived ROS, thromboxane or $\alpha$-adrenergic tone, as it was not suppressed by L-NAME, indomethacin or phentolamine, as their respective inhibitors.

Finally, this study has methodological limitations that may preclude extending the findings to the human neonate in so far as the pathogenesis of NEC is concern. We only studied newborn rats at the end of the first week of life. The diameter of 5-7 d of age rats' mesenteric arteries is very small $(\sim 80$ $\mu \mathrm{m})$, making the study of younger animals very challenging and possibly inaccurate with the used wire myograph technique. Thus, we cannot further speculate on whether the BH4-induced mesenteric arterial vasodilation is agedependent during the first week of life. However, clinically, NEC is usually diagnosed in neonates at a median age of $15 \mathrm{~d}$ (25) making the findings of this animal study possibly relevant to neonates beyond the immediate birth period. Similarly, we are unable to study mesenteric arterial branches that perfuse the bowel mucosa given their extremely small caliber.

In summary, the present data suggest that high BH4 content of breast milk, among other factors, may play an important role in NEC prevention. Further studies addressing the newborn plasma levels and breast milk content of BH4 in infants developing this disease, as well as supplementation of formula with this biopterin to a concentration similar to human milk are warranted.

\section{REFERENCES}

1. Lambert DK, Christensen RD, Henry E, Besner GE, Baer VL, Wiedmeier SE, Stoddard RA, Miner CA, Burnett J 2007 Necrotizing enterocolitis in term neonates: data from a multihospital health-care system. J Perinatol 27:437-443

2. Barlow B, Santulli TV 1975 Importance of multiple episodes of hypoxia or cold stress on the development of enterocolitis in an animal model. Surgery 77:687-690 
3. Chan KL, Hui CW, Chan KW, Fung PC, Wo JY, Tipoe G, Tam PK 2002 Revisiting ischemia and reperfusion injury as a possible cause of necrotizing enterocolitis: role of nitric oxide and superoxide dismutase. J Pediatr Surg 37:828-834

4. Clark DA, Fornabaio DM, McNeill H, Mullane KM, Caravella SJ, Miller MJ 1988 Contribution of oxygen-derived free radicals to experimental necrotizing enterocolitis. Am J Pathol 130:537-542

5. Yang YM, Huang A, Kaley G, Sun D 2009 eNOS uncoupling and endothelial dysfunction in aged vessels. Am J Physiol Heart Circ Physiol 297:H1829-H1836

6. Matsubara Y, Gaull GE 1985 Biopterin and neopterin in various milks and infant formulas. Am J Clin Nutr 41:110-112

7. D'Souza A, Fordjour L, Ahmad A, Cai C, Kumar D, Valencia G, Aranda JV, Beharry KD 2010 Effects of probiotics, prebiotics, and synbiotics on messenger RNA expression of caveolin-1, NOS, and genes regulating oxidative stress in the terminal ileum of formula-fed neonatal rats. Pediatr Res 67:526-531

8. Whitehouse JS, Xu H, Shi Y, Noll L, Kaul S, Jones DW, Pritchard KA Jr, Oldham KT, Gourlay DM 2010 Mesenteric nitric oxide and superoxide production in experimental necrotizing enterocolitis. J Surg Res 161:1-8

9. Tegeder I, Costigan M, Griffin RS, Abele A, Belfer I, Schmidt H, Ehnert C, Nejim J, Marian C, Scholz J, Wu T, Allchorne A, Diatchenko L, Binshtok AM, Goldman D, Adolph J, Sama S, Atlas SJ, Carlezon WA, Parsegian A, Lotsch J, Fillingim RB, Maixner W, Geisslinger G, Max MB, Woolf CJ 2006 GTP cyclohydrolase and tetrahydrobiopterin regulate pain sensitivity and persistence. Nat Med 12:12691277

10. Bradford MM 1976 A rapid and sensitive method for the quantitation of microgram quantities of protein utilizing the principle of protein-dye binding. Anal Biochem $72: 248-254$

11. Alemany CA, Oh W, Stonestreet BS 1997 Effects of nitric oxide synthesis inhibition on mesenteric perfusion in young pigs. Am J Physiol 272:G612-G616

12. Crissinger KD, Granger DN 1989 Mucosal injury induced by ischemia and reperfusion in the piglet intestine: influences of age and feeding. Gastroenterology 97:920-926

13. Qu XW, Wang H, Rozenfeld RA, Huang W, Hsueh W 1999 Type I nitric oxide synthase (NOS) is the predominant NOS in rat small intestine. Regulation by platelet-activating factor. Biochim Biophys Acta 1451:211-217
14. Petersson J, Schreiber O, Steege A, Patzak A, Hellsten A, Phillipson M, Holm L 2007 eNOS involved in colitis-induced mucosal blood flow increase. Am J Physiol Gastrointest Liver Physiol 293:G1281-G1287

15. Belik J, Pan J, Jankov RP, Tanswell AK 2004 A bronchial epithelium-derived factor reduces pulmonary vascular tone in the newborn rat. J Appl Physiol 96:1399-1405

16. Qu XW, Thaete LG, Rozenfeld RA, Zhu Y, De Plaen IG, Caplan MS, Hsueh W 2005 Tetrahydrobiopterin prevents platelet-activating factor-induced intestinal hypoperfusion and necrosis: role of neuronal nitric oxide synthase. Crit Care Med 33:1050_ 1056

17. Crissinger KD, Burney DL 1991 Postprandial hemodynamics and oxygenation in developing piglet intestine. Am J Physiol 260:G951-G957

18. Dhondt JL, Delcroix M, Farriaux JP 1982 Unconjugated pteridines in human milk. Clin Chim Acta 121:33-35

19. Iizuka T, Sasaki M, Oishi K, Uemura S, Koike M, Minatogawa Y 1997 Nitric oxide may trigger lactation in humans. J Pediatr 131:839-843

20. Crabtree MJ, Tatham AL, Al-Wakeel Y, Warrick N, Hale AB, Cai S, Channon KM, Alp NJ 2009 Quantitative regulation of intracellular endothelial nitric-oxide synthase (eNOS) coupling by both tetrahydrobiopterin-eNOS stoichiometry and biopterin redox status: insights from cells with tet-regulated GTP cyclohydrolase I expression. J Biol Chem 284:1136-1144

21. Sawabe K, Saeki Y, Ohashi A, Mamada K, Wakasugi KO, Matsuoka H, Hasegawa H 2009 Tetrahydrobiopterin in intestinal lumen: its absorption and secretion in the small intestine and the elimination in the large intestine. J Inherit Metab Dis 32:79-85

22. Ozkan H, Oren H, Erdag N, Cevik N 1994 Breast milk versus infant formulas: effects on intestinal blood flow in neonates. Indian J Pediatr 61:703-709

23. Lang JA, Holowatz LA, Kenney WL 2009 Local tetrahydrobiopterin administration augments cutaneous vasoconstriction in aged humans. J Physiol 587:3967-3974

24. Lang JA, Holowatz LA, Kenney WL 2010 Localized tyrosine or tetrahydrobiopterin supplementation corrects the age-related decline in cutaneous vasoconstriction. J Physiol 588:1361-1368

25. Henderson G, Craig S, Brocklehurst P, McGuire W 2009 Enteral feeding regimens and necrotising enterocolitis in preterm infants: a multicentre case-control study. Arch Dis Child Fetal Neonatal Ed 94:F120-F123 